\title{
Effects of Alpha Adrenergic Blockade upon Coronary Hemodynamics
}

\author{
Arthur E. Orlick, Donald R. Ricci, Edwin L. Alderman, Edward B. Stinson, \\ and Donald C. HARrison, Division of Cardiology and the Department of \\ Cardiovascular Surgery, Stanford University School of Medicine, \\ Stanford, California 94305
}

\begin{abstract}
A в S T R A C T The effect of alpha adrenergic blockade on coronary blood flow regulation at rest was studied in 11 normally innervated patients and 8 cardiac allograft recipients by measuring arterial pressure and coronary sinus blood flow by thermodilution before and after alpha adrenergic blockade with phentolamine. Coronary vascular resistance was calculated by using coronary sinus blood flow and mean arterial pressure, and metabolic demand was estimated by the product of systolic arterial pressure and heart rate. In addition, the coronary sinus blood flow response to tachycardia was examined in 9 innervated patients and 12 denervated patients, with measurements repeated after phentolamine in 8 of the 9 innvervated patients and 6 of the 12 denervated patients. There was a $7.3 \pm 4.4 \%$ increase in coronary sinus blood flow in the innervated patients in response to alpha blockade, whereas the transplanted patients had an $8.2 \pm 1.8 \%$ fall in coronary sinus blood flow, despite equivalent changes in rate pressure product. The innervated patients also demonstrated a significantly greater increase in coronary sinus blood flow than did the transplanted patients during the first $5 \mathrm{~s}$ of an abrupt increase in heart rate $(26 \pm 4 \mathrm{vs} .8 \pm 2.5 \mathrm{ml} / \mathrm{min}, P<0.001)$. This early response was blunted after alpha adrenergic blockade. We conclude that there is basal alpha adrenergic tone present on the coronary vasculature in man that is withdrawn by a sudden increase in heart rate.
\end{abstract}

This work was presented in part at the 26th Annual Scientific Session of the American College of Cardiology in Las Vegas, Nevada, 7-10 March 1977.

Dr. Ricci was supported by a grant from the Canadian Heart Association.

Received for publication $18 \mathrm{July} 1977$ and in revised form 17 March 1978.

\section{INTRODUCTION}

In the normal heart, coronary blood flow is matched to myocardial metabolic work requirement. Changes in metabolic demand are thought to produce changes in coronary blood flow through mediation of metabolic, autonomic, and myogenic factors (1-4). In the stable state, metabolic regulators such as adenosine and prostaglandins are thought to be more important than neurogenic and myogenic factors (1-4), though neurogenic mechanisms have been shown to alter coronary flow in awake and anesthetized animals as well. Both sympathetic and parasympathetic activation in animals produce coronary vasoconstriction and vasodilation (5-21), with a recent study suggesting the presence of alpha adrenergic tone on the coronary vasculature in the resting state (15). In man, reflex coronary vasoconstriction in response to a cold stimulus, mediated through an alpha adrenergic mechanism, has also been demonstrated (22).

Thus, activation of the autonomic nervous system alters coronary flow, but its role in mediating changes in coronary blood flow in response to changes in demand is ill defined. It is likely that dynamic changes in coronary hemodynamics in response to alterations in metabolic demand involve an immediate autonomic adjustment which is then overridden by metabolic autoregulation, a sequence reminiscent of the classic defense reaction (23).

To further define the role of the autonomic nervous system in regulating coronary blood flow in man, we studied the effect of alpha adrenergic blockade upon both resting coronary hemodynamics and the immediate changes in coronary hemodynamics associated with tachycardia. The results indicate that the alpha adrenergic system significantly contributes to resting 
coronary blood flow in man, and that the earliest measurable increase in coronary blood flow after augmentation of metabolic demand is facilitated by withdrawal of alpha adrenergic tone.

\section{METHODS}

\section{Coronary and systemic hemodynamic measurements}

Coronary sinus blood flow was measured by the thermodilution technique of Ganz et al. (24). Catheter insertions were performed either percutaneously or via cutdown into a superficial left antecubital vein, or percutaneously into the right internal jugular vein. The catheter (Wilton Webster Laboratories, Altadena, Calif.) was firmly fixed at the venous entry site to ensure a stable position throughout the study. The catheter tip was positioned deep within the coronary sinus, at least $3 \mathrm{~cm}$ from the ostium, and contrast was periodically injected to confirm a stable catheter position. Infusion of $5 \%$ dextrose solution at a rate of $50-55 \mathrm{ml} / \mathrm{min}$ was used. In our laboratory, duplicate determinations of coronary sinus blood flow in the same patient agree to within $4 \pm 8.6 \%$ (mean $\pm \mathrm{SD}$ ). Coronary sinus flow and arterial pressure were measured with the patients in the same body position (25). Arterial pressure was measured with a Statham P-23Db transducer (Statham Instruments, Inc., Oxnard, Calif.) through a 7.4 F Judkins coronary catheter or a $6.7 \mathrm{~F}$ sidehole pigtail catheter positioned in the central aorta, or a PE-160 catheter inserted into the brachial artery. Systolic pressure in the cardiac recipients was obtained by averaging three beats to account for the changes in arterial pressure produced by the lack of synchronization of atrial and ventricular contraction in these patients. Arterial and venous oxygen contents were measured by the spectrophotometric method of Gordy and Drabkin (26). Pressure, flow, and electrocardiographic traces were recorded on a strip chart optical recording system. Mean arterial pressure was calculated by using the following formula (27):

$$
\frac{\text { Systolic }+2 \text { (diastolic) }}{3}
$$

Coronary vascular resistance was calculated as the quotient of mean arterial pressure and coronary sinus blood flow. Cardiac metabolic demand was estimated by the product of heart rate and systolic arterial pressure $(28,29)$.

\section{Patient characteristics}

We studied 11 innervated patients (6 female and 5 male) ranging in age from 28 to $56 \mathrm{yr}$, and 12 denervated cardiac allograft recipients (all male), ranging in age from 18 to $56 \mathrm{yr}$. In the innervated group, seven patients had atypical chest pain and arteriographically normal coronary arteries. Three had $>70 \%$ stenosis of the right coronary artery only, and one had mitral insufficiency.

The cardiac allograft recipients were studied at a time of clinical stability, approximately $4 \mathrm{mo}$ to $6.5 \mathrm{yr}$ postoperatively. All recipients were without graft rejection at the time of the study, as documented by a right ventricular endomyocardial biopsy. Six of the recipients had normal coronary arteries, documented arteriographically within 12 mo of the study. The remaining patients did not have angiographic evaluation. There was no evidence of efferent autonomic cardiac innervation in any of the recipients studied, a finding consistent with earlier work documenting the persistence of autonomic denervation of cardiac allografts in man several years after transplantation $(30,31)$.

All the patients gave informed consent in accordance with the regulations of the Stanford University Medical Committee on the Use of Human Subjects in Research. There were no complications during the investigation.

\section{Study protocols}

The effect of alpha adrenergic blockade on resting coronary hemodynamics. In this part of our study, we examined the contribution that the alpha adrenergic component makes to resting coronary blood flow by monitoring the response of coronary hemodynamics to alpha adrenergic blockade. Coronary sinus flow and arterial pressure were measured continuously in 13 patients before and for $3 \mathrm{~min}$ after administration of a 5-mg intravenous bolus of phentolamine mesylate (Regitine; Ciba Pharmaceutical Company, Summit, N. J.). In six patients, measurements were obtained immediately before and again at 3 min after drug administration. In 9 of the 11 innervated patients, heart rate was controlled by atrial pacing at 20 beats per minute above the resting sinus rate. Measurements used for analysis were the lowest coronary blood flow recorded in the first $3 \mathrm{~min}$ after drug administration. Coronary arteriovenous oxygen differences were measured at control only.

The effect of rapid atrial pacing on coronary hemodynamics. In this part of the study, we examined how the alpha adrenergic system contributes to the earliest adjustment in coronary blood flow by using rapid atrial pacing to suddenly increase metabolic demand. Coronary sinus blood flow and arterial pressure were monitored continuously during the abrupt onset of rapid atrial pacing at a rate approximately 45 beats per minute above the basal sinus rate. The changes in coronary sinus flow, mean arterial pressure, and rate pressure product from prepaced control were followed for $25 \mathrm{~s}$. Seven innervated patients and six allograft recipients were given phentolamine mesylate, $5 \mathrm{mg}$ intravenously, and the pacing was repeated.

Student's $t$ test for paired and unpaired data with equal variance was used for statistical comparisons; results are expressed as mean values \pm SEM.

\section{RESULTS}

Effect of alpha adrenergic blockade on resting coronary vascular resistance. Table I summarizes the data for the innervated and denervated patients before and after alpha adrenergic blockade. Before alpha blockade the innervated group had a higher resting coronary vascular resistance when compared with the denervated patients $(0.90 \pm 0.09$ vs. $0.68 \pm 0.06 \mathrm{U}$, $P=0.05)$, despite equivalent rate pressure products in both groups. In addition, the innervated patients had a higher coronary arteriovenous oxygen difference $(11.79 \pm 0.53$ vs. $9.78 \pm 0.50$ vol $\%, P<0.02)$. These control data are graphically presented in Fig. 1. Fig. 2 demonstrates representative changes produced by alpha blockade in one innervated and one denervated patient. Despite both patients having had similar decreases in arterial pressure, the innervated patient had a $50 \mathrm{ml} / \mathrm{min}$ rise in coronary sinus blood flow, whereas the denervated patient had a reduction in coronary 
TABLE I

The Effect of Alpha Adrenergic Blockade on Coronary Hemodynamics and Metabolic Demand

\begin{tabular}{|c|c|c|c|c|c|c|c|c|c|c|c|}
\hline \multicolumn{12}{|c|}{ Innervated patients } \\
\hline \multirow{2}{*}{$\begin{array}{c}\text { Patient } \\
\text { no. }\end{array}$} & \multicolumn{2}{|c|}{$\mathrm{CBF}$} & \multicolumn{2}{|c|}{ CVR } & \multirow{2}{*}{$\begin{array}{l}\Delta \mathrm{AA}-\mathrm{VO}_{2} \\
\mathrm{C} \text { only }\end{array}$} & \multicolumn{2}{|c|}{ HR } & \multicolumn{2}{|c|}{ MAP } & \multicolumn{2}{|c|}{ SAP·HR } \\
\hline & C & $\alpha \mathbf{B}$ & C & $\alpha \mathrm{B}$ & & C & $\alpha \mathbf{B}$ & C & $\alpha \mathbf{B}$ & C & $\alpha \mathbf{B}$ \\
\hline & \multicolumn{2}{|c|}{$\mathrm{ml} / \mathrm{min}$} & \multicolumn{2}{|c|}{$m m \mathrm{Hg} / m \mathrm{l} / \mathrm{min}$} & vol \% & \multicolumn{2}{|c|}{ beats/min } & \multicolumn{2}{|c|}{$m m \mathrm{Hg}$} & \multicolumn{2}{|c|}{$\times 10^{3}$} \\
\hline 1 & 175 & 224 & 0.57 & 0.40 & 9.18 & 107 & 107 & 100 & 89 & $13 \cdot 69$ & $12 \cdot 20$ \\
\hline 2 & 113 & 148 & 0.77 & 0.53 & 11.66 & 120 & 120 & 87 & 79 & $13 \cdot 68$ & $11 \cdot 76$ \\
\hline 3 & 118 & 107 & 0.78 & 0.72 & 13.56 & 114 & 114 & 92 & 77 & $12 \cdot 31$ & $10 \cdot 26$ \\
\hline 4 & 68 & 76 & 1.69 & 1.28 & 11.65 & 73 & 76 & 115 & 97 & $9 \cdot 02$ & $8 \cdot 20$ \\
\hline 5 & 115 & 127 & 0.72 & 0.51 & 9.62 & 79 & 79 & 83 & 65 & $9 \cdot 80$ & $7 \cdot 90$ \\
\hline 6 & 95 & 95 & 1.20 & 1.02 & 11.21 & 102 & 102 & 114 & 97 & $14 \cdot 90$ & $12 \cdot 60$ \\
\hline 7 & 146 & 121 & 0.84 & 0.94 & - & 84 & 84 & 123 & 114 & $14 \cdot 62$ & $13 \cdot 60$ \\
\hline 8 & 112 & 125 & 0.93 & 0.76 & 13.56 & 60 & 86 & 104 & 95 & $8 \cdot 34$ & $10 \cdot 40$ \\
\hline 9 & 130 & 135 & 0.85 & 0.81 & 13.41 & 96 & 96 & 111 & 110 & $14 \cdot 20$ & $14 \cdot 0$ \\
\hline 10 & 149 & 171 & 0.77 & 0.57 & 10.51 & 64 & 80 & 115 & 97 & $11 \cdot 0$ & $11 \cdot 52$ \\
\hline 11 & 177 & 169 & 0.76 & 0.67 & 13.55 & 102 & 102 & 135 & 114 & $19 \cdot 38$ & $16 \cdot 52$ \\
\hline Mean & 127 & 136 & 0.90 & 0.75 & 11.79 & 91 & 95 & 107 & 94 & $12 \cdot 81$ & $11 \cdot 72$ \\
\hline SEM & 10 & 12 & 0.09 & 0.08 & 0.53 & 6 & 5 & 5 & 5 & 0.96 & $0 \cdot 76$ \\
\hline$P$ & \multicolumn{2}{|c|}{$<0.20$} & \multicolumn{2}{|c|}{$<0.005$} & 一 & \multicolumn{2}{|c|}{$<0.20$} & \multicolumn{2}{|c|}{$<0.001$} & \multicolumn{2}{|c|}{$<0.005$} \\
\hline \multicolumn{12}{|c|}{ Denervated patients } \\
\hline 12 & 107 & 114 & 0.81 & 0.66 & 11.51 & 123 & 123 & 87 & 76 & $13 \cdot 90$ & $12 \cdot 40$ \\
\hline 13 & 98 & 93 & 0.93 & 0.88 & 11.22 & 94 & 94 & 91 & 82 & $11 \cdot 79$ & $10 \cdot 73$ \\
\hline 14 & 140 & 126 & 0.56 & 0.63 & 10.03 & 108 & 108 & 79 & 79 & $10 \cdot 89$ & $10 \cdot 96$ \\
\hline 15 & 160 & 141 & 0.46 & 0.45 & 9.01 & 115 & 115 & 73 & 64 & - & - \\
\hline 16 & 110 & 116 & 0.87 & 0.72 & 10.39 & 96 & 96 & 96 & 83 & $11 \cdot 16$ & $10 \cdot 36$ \\
\hline 17 & 167 & 137 & 0.74 & 0.77 & 10.16 & 100 & 100 & 123 & 106 & $16 \cdot 80$ & $14 \cdot 60$ \\
\hline 18 & 190 & 169 & 0.58 & 0.55 & 7.14 & 111 & 111 & 111 & 93 & $15 \cdot 76$ & $13 \cdot 80$ \\
\hline 19 & 197 & 180 & 0.50 & 0.52 & 8.74 & 90 & 90 & 99 & 93 & $11 \cdot 16$ & $10 \cdot 53$ \\
\hline Mean & 146 & 135 & 0.68 & 0.65 & 9.78 & 105 & 105 & 95 & 85 & $13 \cdot 07$ & $11 \cdot 91$ \\
\hline SEM & 14 & 10 & 0.06 & 0.05 & 0.50 & 12 & 12 & 6 & 5 & 0.92 & $0 \cdot 65$ \\
\hline$P$ & \multicolumn{2}{|c|}{$<0.05$} & \multicolumn{2}{|c|}{$<0.3$} & - & \multicolumn{2}{|c|}{$<1.00$} & \multicolumn{2}{|c|}{$<0.003$} & \multicolumn{2}{|c|}{$<0.01$} \\
\hline
\end{tabular}

Abbreviations: $\mathrm{CBF}=$ coronary sinus blood flow; $\mathrm{CVR}=$ coronary vascular resistance; $\Delta \mathrm{A}-\mathrm{VO}_{2}=$ coronary arteriovenous oxygen difference; $\mathrm{HR}=$ heart rate; $\mathrm{MAP}=$ mean arterial pressure; $\mathrm{SAP} \cdot \mathrm{HR}=$ rate-pressure product; $\mathrm{C}=$ control; $\alpha \mathrm{B}=$ alpha blockade.

sinus flow of $30 \mathrm{ml} / \mathrm{min}$. Fig. 3 portrays the percent changes in rate pressure product and coronary sinus flow produced by alpha blockade in both groups. After alpha blockade in the innervated patients, coronary sinus blood flow increased by $7.3 \pm 4.4 \%$ despite a fall in rate pressure product of $7.1 \pm 3.8 \%$. This effect was directionally opposite to that produced in the denervated group, in which an $8.2 \pm 1.8 \%$ decrease in rate pressure product was associated with a $6.6 \pm 3.0 \%$ reduction in coronary sinus flow.

The effect of rapid atrial pacing on coronary sinus blood flow. Tables II and III present individual measurements of coronary sinus blood flow, mean arterial pressure, and rate pressure product before and after alpha blockade. Although coronary sinus flow and arterial pressure were continuously recorded for $25 \mathrm{~s}$ after the initiation of rapid pacing, only the prepaced control, 5-s and 20-s values are listed, as these time intervals offered the best discrimination between the early and late coronary sinus flow changes when the denervated and innervated patients were examined as groups. Fig. 4 portrays the changes in coronary sinus flow produced by rapid atrial pacing. $5 \mathrm{~s}$ after the onset of pacing, coronary sinus flow in the innervated patients rose $26 \pm 4 \mathrm{ml} / \mathrm{min}$ in contrast to the denervated patients, who exhibited a significantly smaller increment in coronary sinus flow of $8 \pm 2.5$ $\mathrm{ml} / \mathrm{min}$. By $20 \mathrm{~s}$ both groups had similar augmentations in coronary sinus flow, constituting $57.4 \pm 14$ and 52 $\pm 10.6 \mathrm{ml} / \mathrm{min}$ above control levels, respectively. Alpha blockade in the innervated patients produced a blunting of the early increment in coronary sinus flow, so 

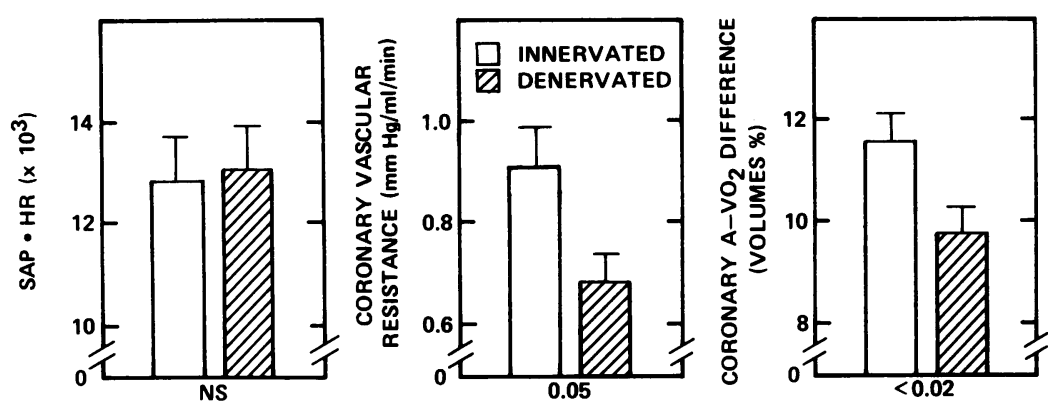

FIGURE 1 A comparison of rate-pressure product (SAP $\cdot$ HR), coronary vascular resistance, and coronary arteriovenous oxygen difference $\left(\mathrm{A}-\mathrm{VO}_{2}\right)$ difference in both patient groups before alpha adrenergic blockade. At similar SAP - HR, note the higher coronary vascular resistance and higher coronary $\mathrm{A}-\mathrm{VO}_{2}$ difference in the innervated patients.

that denervated and alpha-blocked innervated patients showed similar increases in flow at $5 \mathrm{~s}$ of $9 \pm 4.5$ and $8 \pm 2.5 \mathrm{ml} / \mathrm{min}$, respectively. The 20 -s change in both groups also remained similar. Alpha blockade in the denervated patients did not alter early or late coronary sinus flow change. The above changes were observed despite similar changes in rate pressure at 5 and $20 \mathrm{~s}$ in all groups, as noted in Tables II and III.

\section{DISCUSSION}

Although previous studies in animals suggest that the autonomic nervous system plays a significant role in altering coronary blood flow, its role in man is less clear. A recent report documents alpha adrenergic participation in reflex changes in coronary vascular resistance in response to a cold stimulus (22). Nevertheless, the presence of resting neurogenic tone in human coronary vessels, and its functional significance during physiologic stresses, has yet to be established. The cardiac allograft recipient, lacking innervation to both coronary vessels and ventricular myocardium, provides a unique opportunity to study this interaction in man.

The first part of our study provides three lines of evidence which suggest that the alpha adrenergic system significantly contributes to resting coronary hemodynamics in man: $(a)$ the higher coronary vascular resistance in the innervated patients; $(b)$ the wider coronary arteriovenous oxygen difference in the innervated patients; and $(c)$ the directionally opposite response in coronary sinus flow after alpha adrenergic

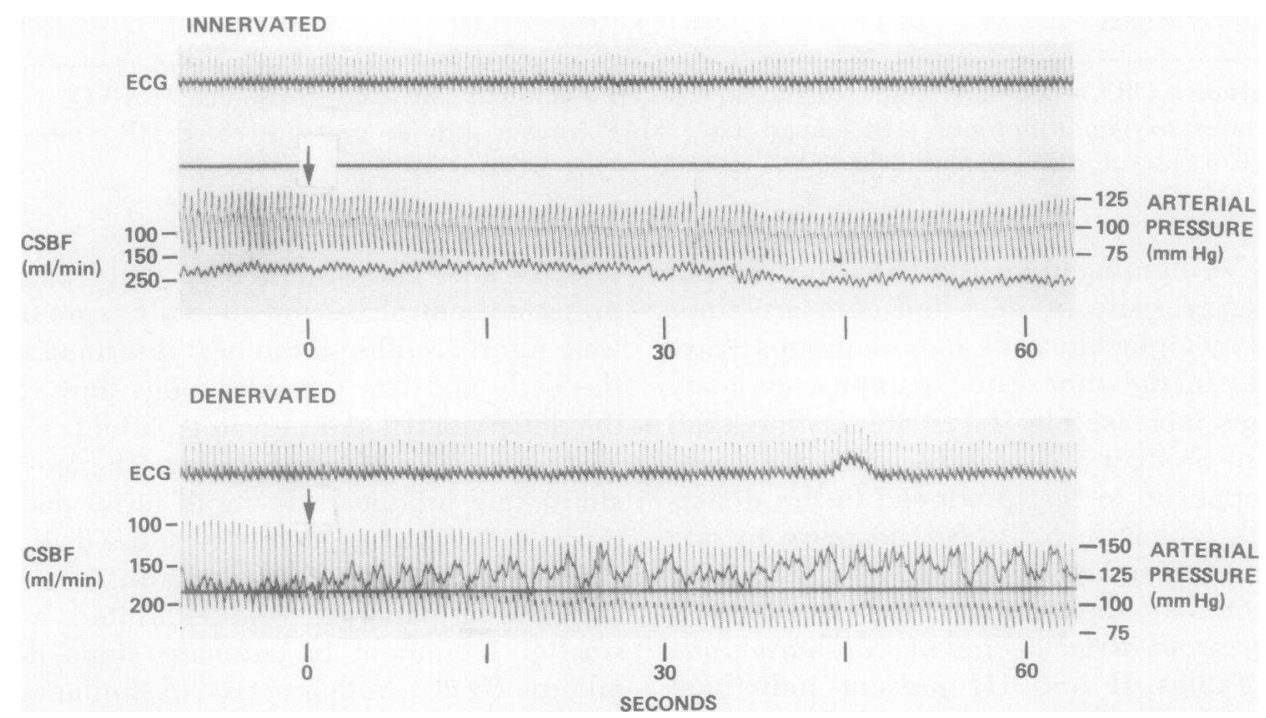

FIGURE 2 Representative records demonstrating the effect of alpha blockade on coronary sinus blood flow (CSBF) and arterial pressure in one innervated patient (top) and one denervated patient (bottom). Phentolamine is injected at the arrow. Directionally opposite changes in CSBF are illustrated in response to a similar reduction in arterial pressure, ECG, electrocardiogram. 


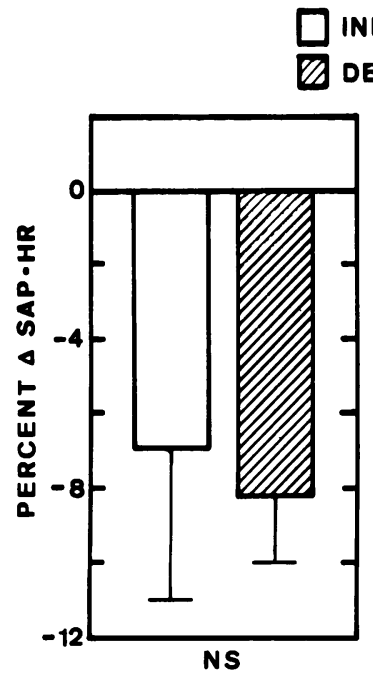

INNERVATED $(n=11)$

DENERVATED $(n=8)$

Figure 3 A comparison of the change in rate-pressure product (SAP.HR) and coronary sinus blood flow in both patient groups after alpha adrenergic blockade. Note the directionally opposite changes in coronary sinus flow despite similar reductions in SAP. HR. blockade in the innervated and denervated patients. These data, however, need to be interpreted in light of the following considerations. Inasmuch as nonadrenergic autoregulatory mechanisms $(32,33)$ were operative in both patient groups, differences in coronary resistance may be related, at least in part, to differences in perfusion pressure. Similarly, the difference in coronary resistance between the groups may be related to differences in ventricular tissue mass. To examine this possibility, left ventricular wall mass was calculated using the left ventricular angiogram (34) in five denervated and six innervated patients included in this study. The denervated group has a left mass of $136.3 \pm 20.6 \mathrm{~g}$ vs. $109.6 \pm 17.9 \mathrm{~g}$ in the innervated group, and though not statistically significant, this may, in fact, be the sole explanation for the higher flow noted in the denervated group. A systemic alteration in the position of the thermodilution catheter within the coronary sinus in the denervated patients may have also contributed to a higher coronary sinus flow in this group; however, every effort was made to place the catheter in the same position in the coronary

TABLE II

Changes in Coronary Blood Flow and Metabolic Demand Produced by Atrial Pacing in Innervated Patients

\begin{tabular}{|c|c|c|c|c|c|c|c|c|c|c|c|}
\hline \multicolumn{12}{|c|}{ Before alpha adrenergic blockade } \\
\hline \multirow[b]{2}{*}{ Patient } & \multicolumn{3}{|c|}{ CBF } & \multicolumn{3}{|c|}{ MAP } & \multicolumn{3}{|c|}{ SAP· HR } & \multicolumn{2}{|c|}{ HR } \\
\hline & C & $5 \mathrm{~s}$ & $20 \mathrm{~s}$ & c & $5 \mathrm{~s}$ & $20 \mathrm{~s}$ & C & $5 \mathrm{~s}$ & $20 \mathrm{~s}$ & C & $\mathbf{P}$ \\
\hline & \multicolumn{3}{|c|}{$\mathrm{ml} / \mathrm{min}$} & \multicolumn{3}{|c|}{$m m \mathrm{Hg}$} & \multicolumn{3}{|c|}{$\times 10^{3}$} & \multicolumn{2}{|c|}{ beats/min } \\
\hline 1 & 161 & 207 & 235 & 128 & 130 & 128 & $18 \cdot 65$ & $23 \cdot 23$ & $23 \cdot 25$ & 100 & 128 \\
\hline 2 & 63 & 97 & 131 & 85 & 87 & 88 & $8 \cdot 93$ & $13 \cdot 83$ & $13 \cdot 81$ & 72 & 118 \\
\hline 3 & 137 & 150 & 160 & 111 & 131 & 114 & $10 \cdot 79$ & $18 \cdot 36$ & $16 \cdot 12$ & 65 & 102 \\
\hline 4 & 111 & 124 & 159 & 102 & 106 & 108 & $13 \cdot 25$ & $21 \cdot 06$ & $21 \cdot 84$ & 96 & 156 \\
\hline 5 & 121 & 143 & 166 & 91 & 94 & 87 & $8 \cdot 28$ & $14 \cdot 07$ & 13.06 & 72 & 134 \\
\hline 6 & 92 & 122 & 154 & 104 & 120 & 110 & $9 \cdot 75$ & $18 \cdot 76$ & $16 \cdot 35$ & 75 & 134 \\
\hline 7 & 157 & 199 & 234 & 93 & 108 & 104 & $10 \cdot 08$ & $17 \cdot 16$ & $16 \cdot 94$ & 80 & 124 \\
\hline 8 & 195 & 214 & 252 & 71 & 71 & 71 & $7 \cdot 14$ & $11 \cdot 96$ & $11 \cdot 96$ & 70 & 130 \\
\hline 9 & 101 & 118 & 157 & 87 & 102 & 102 & $7 \cdot 18$ & $13 \cdot 83$ & $13 \cdot 99$ & 57 & 100 \\
\hline Mean & 126 & 153 & 183 & 97 & 105 & 99 & $10 \cdot 45$ & $16 \cdot 91$ & $16 \cdot 14$ & 76 & 125 \\
\hline SEM & 13.5 & 14 & 14.8 & 5.5 & 6.6 & 5.6 & 1.20 & 1.25 & 1.36 & 4.6 & 5.7 \\
\hline$P$ & \multicolumn{3}{|c|}{$<0.001<0.001$} & \multicolumn{2}{|c|}{$<0.02$} & NS & \multicolumn{3}{|c|}{$<0.001$} & \multicolumn{2}{|c|}{$<0.001$} \\
\hline \multicolumn{12}{|c|}{ After alpha adrenergic blockade } \\
\hline 2 & 75 & 90 & 120 & 73 & 73 & 73 & $8 \cdot 34$ & $12 \cdot 15$ & $12 \cdot 15$ & 76 & 125 \\
\hline 3 & 171 & 175 & 171 & 97 & 103 & 105 & $11 \cdot 52$ & $15 \cdot 04$ & $15 \cdot 04$ & 80 & 103 \\
\hline 4 & 130 & 141 & 172 & 105 & 101 & 105 & $15 \cdot 78$ & $20 \cdot 90$ & $22 \cdot 15$ & 108 & 156 \\
\hline 5 & 122 & 122 & 145 & 84 & 85 & 76 & $8 \cdot 24$ & $13 \cdot 0$ & $11 \cdot 93$ & 77 & 134 \\
\hline 6 & 124 & 124 & 164 & 102 & 110 & 105 & $11 \cdot 0$ & $17 \cdot 29$ & $16 \cdot 23$ & 86 & 133 \\
\hline 7 & 154 & 185 & 216 & 95 & 101 & 101 & $12 \cdot 65$ & $15 \cdot 50$ & $15 \cdot 74$ & 102 & 123 \\
\hline 9 & 115 & 115 & 130 & 75 & 75 & 75 & $8 \cdot 53$ & $13 \cdot 39$ & $13 \cdot 39$ & 79 & 124 \\
\hline Mean & 127 & 136 & 160 & 90 & 93 & 91 & $10 \cdot 86$ & $15 \cdot 32$ & $15 \cdot 23$ & 87 & 128 \\
\hline SEM & 11.5 & 12.8 & 12.1 & 4.9 & 5.8 & 5.6 & 1.1 & 1.1 & 1.3 & 4.9 & 6.0 \\
\hline$P$ & \multicolumn{3}{|c|}{$<0.1<$} & \multicolumn{2}{|c|}{ NS } & NS & \multicolumn{3}{|c|}{$<0.001<0.001$} & \multicolumn{2}{|c|}{$<0.001$} \\
\hline
\end{tabular}

$P=$ pacing. Other abbreviations as in Table $I$. 
TABLE III

Changes in Coronary Blood Flow and Metabolic Demand Produced by Atrial Pacing in Denervated Patients

\begin{tabular}{|c|c|c|c|c|c|c|c|c|c|c|c|}
\hline \multicolumn{12}{|c|}{ Before alpha adrenergic blockade } \\
\hline \multirow[b]{2}{*}{ Patient } & \multicolumn{3}{|c|}{ CBF } & \multicolumn{3}{|c|}{ MAP } & \multicolumn{3}{|c|}{ SAP·HR } & \multicolumn{2}{|c|}{ HR } \\
\hline & C & $5 \mathrm{~s}$ & $20 \mathrm{~s}$ & C & $5 \mathrm{~s}$ & $20 \mathrm{~s}$ & C & $5 \mathrm{~s}$ & $20 \mathrm{~s}$ & C & $\mathbf{P}$ \\
\hline & \multicolumn{3}{|c|}{$m l / m i n$} & \multicolumn{3}{|c|}{$m m \mathrm{Hg}$} & \multicolumn{3}{|c|}{$\times 10^{3}$} & \multicolumn{2}{|c|}{ beats/min } \\
\hline 12 & 127 & 130 & 148 & 82 & 89 & 89 & $13 \cdot 80$ & $17 \cdot 22$ & $17 \cdot 22$ & 120 & 140 \\
\hline 13 & 104 & 127 & 192 & 94 & 98 & 101 & $11 \cdot 83$ & $18 \cdot 02$ & $19 \cdot 16$ & 91 & 143 \\
\hline 14 & 143 & 146 & 152 & 78 & 77 & 68 & $10 \cdot 91$ & $14 \cdot 20$ & $12 \cdot 95$ & 108 & 156 \\
\hline 16 & 117 & 113 & 133 & 92 & 95 & 91 & $10 \cdot 26$ & $14 \cdot 61$ & $14 \cdot 11$ & 91 & 126 \\
\hline 17 & 146 & 146 & 179 & 122 & 128 & 119 & $17 \cdot 09$ & $23 \cdot 68$ & $22 \cdot 20$ & 103 & 148 \\
\hline 18 & 184 & 201 & 259 & 109 & 99 & 101 & $14 \cdot 74$ & $17 \cdot 33$ & $17 \cdot 63$ & 110 & 152 \\
\hline 19 & 211 & 228 & 341 & 99 & 106 & 102 & $11 \cdot 25$ & $17 \cdot 55$ & $16 \cdot 87$ & 90 & 135 \\
\hline 20 & 150 & 156 & 172 & 102 & 101 & 101 & $13 \cdot 40$ & $16 \cdot 38$ & $15 \cdot 73$ & 100 & 130 \\
\hline 21 & 77 & 86 & 121 & 95 & 93 & 97 & $10 \cdot 75$ & $17 \cdot 28$ & $17 \cdot 86$ & 84 & 144 \\
\hline 22 & 146 & 156 & 236 & 104 & 111 & 111 & $16 \cdot 13$ & $24 \cdot 33$ & $24 \cdot 33$ & 109 & 158 \\
\hline 23 & 172 & 186 & 213 & 111 & 115 & 111 & $14 \cdot 89$ & $21 \cdot 90$ & $21 \cdot 30$ & 102 & 150 \\
\hline 24 & 135 & 133 & 190 & 95 & 100 & 91 & $10 \cdot 44$ & $17 \cdot 28$ & $16 \cdot 12$ & 90 & 144 \\
\hline Mean & 143 & 151 & 195 & 98.5 & 101 & 98.5 & $12 \cdot 96$ & $18 \cdot 32$ & $17 \cdot 96$ & 100 & 144 \\
\hline SEM & 10.3 & 11.3 & 17.7 & 3.5 & 3.8 & 3.8 & 0.68 & 0.94 & 0.96 & \multirow{2}{*}{\multicolumn{2}{|c|}{${ }^{3}<0.0005^{3}$}} \\
\hline$P$ & \multicolumn{3}{|c|}{$<0.0025<0.0005$} & NS & \multicolumn{2}{|c|}{ NS } & \multicolumn{2}{|c|}{$<0.0005<$} & 0005 & & \\
\hline \multicolumn{12}{|c|}{ After alpha adrenergic blockade } \\
\hline 13 & 93 & 118 & 146 & 82 & 91 & 91 & $10 \cdot 73$ & $16 \cdot 73$ & $16 \cdot 73$ & 93 & 143 \\
\hline 14 & 124 & 126 & 133 & 79 & 69 & 66 & $10 \cdot 96$ & $13 \cdot 57$ & $13 \cdot 19$ & 108 & 156 \\
\hline 16 & 120 & 120 & 135 & 95 & 95 & 95 & $11 \cdot 90$ & $15 \cdot 62$ & $15 \cdot 12$ & 96 & 126 \\
\hline 17 & 137 & 143 & 175 & 106 & 111 & 111 & $14 \cdot 60$ & $21 \cdot 46$ & $20 \cdot 58$ & 100 & 147 \\
\hline 18 & 177 & 178 & 201 & 92 & 96 & 96 & $14 \cdot 39$ & $19 \cdot 80$ & $19 \cdot 80$ & 109 & 150 \\
\hline 23 & 168 & 182 & 217 & 93 & 90 & 90 & $13 \cdot 80$ & $16 \cdot 72$ & $16 \cdot 72$ & 115 & 152 \\
\hline Mean & 137 & 145 & 168 & 91 & 92 & 92 & $12 \cdot 73$ & $17 \cdot 31$ & $17 \cdot 02$ & 104 & 146 \\
\hline SEM & 12.8 & 11.8 & 14.5 & 4 & 5.5 & 5.6 & 0.71 & 1.20 & 1.13 & \multirow{2}{*}{\multicolumn{2}{|c|}{${ }_{<0.001}^{3.5}$}} \\
\hline$P$ & \multicolumn{2}{|c|}{ NS } & $<0.01$ & \multicolumn{2}{|c|}{ NS } & NS & \multicolumn{2}{|c|}{$<0.001$} & 001 & & \\
\hline
\end{tabular}

Abbreviations as in Table I and Table II.

sinus in each patient to minimize any differences in flow resulting from differences in volume of tissue perfused.

The second line of evidence suggesting resting alpha adrenergic tone relates to the finding of a narrower coronary arteriovenous oxygen difference in the denervated patients. This finding, however, may only reflect a reduced oxygen-carrying capacity in this group, in that the denervated patients had a hemoglobin level of $12.1 \pm 0.4 \mathrm{~g}$ vs. $13.5 \pm 0.4 \mathrm{~g}$ in the innervated group, $P<0.05$. If we accept the fact that coronary blood flow is adjusted to maintain a certain level of tissue oxygenation, and that coronary venous oxygen saturation adequately reflects this level (assuming no systematic alteration in the oxygen dissociation curve), if follows that for similar myocardial oxygen demands both groups should have similar coronary venous oxygen saturations. This, in fact, was the case with the denervated patients having a coronary sinus oxygen saturation of $34.8 \pm 3.3 \%$ and the innervated group a coronary sinus oxygen saturation of $32.3 \pm 1.33 \%$. This analysis, however, fails to account for potential differences in capillarity between the groups (35). Thus, if the denervated patients had more "open" capillaries than the innervated group, one might predict a higher tissue oxygen level, despite similar coronary venous oxygen saturations. Nevertheless, the above considerations do not adequately explain the differences in the coronary sinus flow responses to alpha adrenergic blockade. That is, at a time when there was a significant reduction in metabolic demand resulting from the fall in arterial pressure, the innervated patients had a $7.3 \%$ augmentation in coronary sinus flow. This was in contrast to the denervated group where a $6.6 \%$ reduction in coronary sinus flow was noted. Reduced metabolic demand, per se, would be 


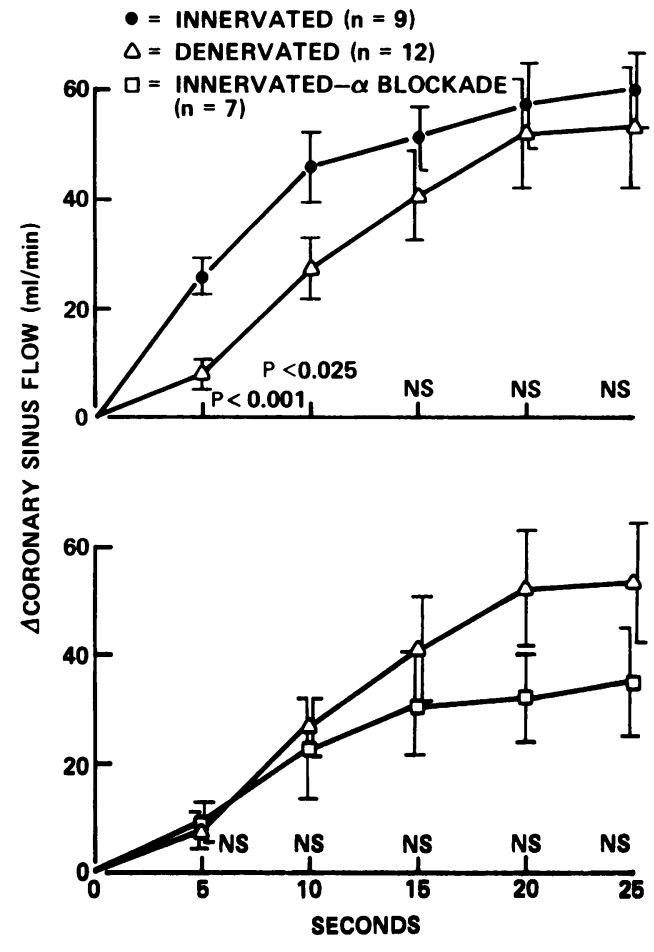

FIGURE 4 Comparison of the time-course of the change in coronary sinus blood flow produced by rapid atrial pacing in innervated patients $(\Theta)$, denervated patients $(\Delta)$, and innervated patients after alpha blockade $(\square)$. See text for details.

expected to result in a decrease rather than an increase in coronary sinus flow. Although phentolamine has been shown to have positive inotropic effects (36), this effect should be similar in both groups, as a recent report has shown that myocardial catecholamine output during physiologic maneuvers is relatively small when compared with the total output measured (37).

Having demonstrated the presence of resting neurogenic tone on the coronary vasculature, we next sought to examine its participation in situations of changing metabolic demand. We hypothesized that the response of the coronary circulation is similar to the peripheral vasodilation that occurs in response to fright, as in the defense reaction. Thus, the sudden imposition of an augmented myocardial metabolic requirement might activate autonomic mechanisms which facilitate the earliest changes in coronary hemodynamics. Metabolic autoregulation would subsequently dominate the response of the coronary vasculature as the increased demand was maintained. Supporting this concept is the finding that innervated patients are able to achieve a greater increase in coronary sinus blood flow in the early (5-s) period after the onset of rapid pacing than are the denervated patients. When alpha blockade is then produced in the innervated patients, the early increase in coronary sinus flow is blunted, and resembles the response to pacing in the denervated group. $20 \mathrm{~s}$ after the onset of rapid pacing, the increase in blood flow is similar in both groups, suggesting the emergence of metabolic predominance in the regulation of coronary resistance at this time.

We recognize that the measurement of coronary sinus blood flow by thermodilution is subject to a number of methodological problems which must be considered when interpreting the results obtained with rapid atrial pacing. These relate to the time constant of the method as well as alterations in catheter position within the sinus during pacing, which would produce artifactual changes in coronary flow. The time constant of the method depends upon the summation of time constants of the temperature sensing and recording system as well as the time constant of the mixing volume. It is recognized that the technique is capable of measuring changes in flow if the cycle length of the change is $>3 \mathrm{~s}(24,38)$. Thus, the detection of a change in coronary sinus flow in $5 \mathrm{~s}$ is well within the capability of the technique. Movement of the catheter to a more proximal position within the sinus, as a result of pacing, might falsely increase the measured coronary sinus flow. However, the catheter motion produced by the pacing alone should be similar in both patient groups and thus mask and not accentuate the group differences. Moreover, fluoroscopic monitoring of the catheter within the sinus at the onset of pacing failed to demonstrate any change in catheter position. In addition, the tip of the catheter was positioned at least $3 \mathrm{~cm}$ from the coronary sinus ostium in all patients, making right atrial admixture unlikely as a source of error (39).

A further consideration in the interpretation of our results relates to the "biological" differences in our patient groups. An implicit assumption in our study is that the innervated patients and the cardiac allograft recipients differ only in the presence or absence of cardiac nerves. The cardiac recipients have had at least one episode of graft rejection and are maintained on immunosuppressive agents, both of which could theoretically alter the responsiveness of the coronary vasculature. Nevertheless, both groups had similar changes in coronary hemodynamics in response to a stable increase in metabolic demand produced by pacing, suggesting to us that differences in the responsiveness of the coronary vasculature is an unlikely explanation for our findings. Additionally, all studies in the cardiac recipients were performed at a time of clinical stability and in the absence of graft rejection, as documented by a normal right ventricular endomyocardial biopsy.

Thus, our findings show that the alpha adrenergic system significantly contributes to resting coronary 
hemodynamics in man. In addition, withdrawal of alpha adrenergic tone facilitates the earliest increases in coronary sinus flow when an augmented metabolic demand is produced. The mechanism responsible for the immediate withdrawal of alpha adrenergic tone at the onset of pacing-induced tachycardia is unknown. However, based upon the mechanisms responsible for other cardiovascular-adaptive responses, a reflex mechanism would seem likely, with the receptors of the afferent limb located in the left ventricle, aorta, or carotid bifurcation.

\section{ACKNOWLEDGMENTS}

We would like to thank Dr. Eric Feigl and Dr. Fancis J. Klocke for their helpful suggestions and criticism; Liz Stone, Bev Forster, Michelle Steiner, Jeanne Pope, and Marilyn Riggs for their technical assistance; and Dorothy McCain and Gretchen Selzer for aiding in the preparation of this manuscript.

This work was supported, in part, by National Institutes of Health grant HL-5866.

\section{REFERENCES}

1. Klocke, F. J., R. E. Mates, D. P. Copley, and A. E. Orlick. 1976. Physiology of the coronary circulation in health and coronary artery disease. In Progress in Cardiology. P. N. Yu and J. F. Goodwin, editors. Lea \& Febiger, Philadelphia. 1-17.

2. Berne, R. M. 1964. Regulation of coronary blood flow. Physiol. Rev. 44: 1-29.

3. Berne, R. M., and R. Rubio. 1974. Regulation of coronary blood flow. Adv. Cardiol. 12: 303-317.

4. Berne, R. M. 1974. The coronary circulation. In Mammalian Myocardium, G. A. Langer and A. Brady, editors, John Wiley \& Sons, Inc., New York. 251-281.

5. Berne, R. M., H. DeGeest, and M. N. Levy. 1965. Influence of the cardiac nerves on coronary resistance. Am. J. Physiol. 208: 763-769.

6. Feigl, E. O. 1967. Sympathetic control of coronary circulation. Circ. Res. 20: 262-271.

7. Feigl, E. O. 1968. Carotid sinus reflex control of coronary blood flow. Circ. Res. 23: 223-237.

8. Granata, L., R. A. Olsson, A. Huvos, and D. E. Gregg. 1965. Coronary inflow and oxygen usage following cardiac sympathetic nerve stimulation in unanesthetized dogs. Circ. Res. 16: 114-120.

9. Granata, L., A. Huvos, A. Pasque, and D. E. Gregg. 1969. Left coronary hemodynamics during hemorrhagic hypotension and shock. Am. J. Physiol. 216: 1583-1589.

10. Gregg, D. E., E. M. Khouri, D. E. Donald, H. S. Lowensohn, and S. Pasyk. 1972. Coronary circulation in the conscious dog with cardiac neural ablation. Circ. Res. 31: 129-144.

11. Khouri, E. M., D. E. Gregg, and C. R. Rayford. 1965. Effect of exercise on cardiac output, left coronary flow and myocardial metabolism in the unanesthetized dog. Circ. Res. 17: 427-437.

12. Mark, A. L., F. M. Abboud, P. G. Schmid, D. D. Heistad, and H. E. Mayer. 1972. Differences in direct effects of adrenergic stimuli on coronary, cutaneous and muscular vessels. J. Clin. Invest. 51: 279-287.
13. Pitt, B., E. C. Elliot, and D. E. Gregg. 1967. Adrenergic receptor activity in the coronary arteries of the unanesthetized dog. Circ. Res. 21: 75-84.

14. Rayford, C. R., E. M. Khouri, and D. E. Gregg. 1965. Effect of excitement on coronary and systemic energetics in unanesthetized dogs. Am. J. Physiol. 209: 680-688.

15. Vatner, S. F., D. Franklin, R. L. Van Citters, and E. Braunwald. 1970. Effects of carotid sinus nerve stimulation on the coronary circulation of the conscious dog. Circ. Res. 27: 11-21.

16. Vatner, S. F., D. Franklin, C. B. Higgins, T. Patrick, S. White, and R. L. Van Citters. 1971. Coronary dynamics in unrestrained conscious baboons. Am. J. Physiol. 221: 1396-1401.

17. Vatner, S. F., D. Franklin, and E. Braunwald. 1971. Effects of anesthesia and sleep on circulatory response to carotid sinus nerve stimulation. Am. J. Physiol. 220: 1249-1255.

18. Vatner, S. F., C. B. Higgins, and E. Braunwald. 1974. Effects of norepinephrine on coronary circulation and left ventricular dynamics in the conscious dog. Circ. Res. 34: 812-823.

19. Zuberbuhler, R. C., and D. F. Bohr. 1965. Responses of coronary smooth muscle to catecholamines. Circ. Res. 16: 431-440.

20. Feigl, E. O. 1969. Parasympathetic control of coronary blood flow in dogs. Circ. Res. 25: 509-519.

21. Hackett, J. G., F. M. Abboud, A. L. Mark, P. G. Schmid, and D. D. Heistad. 1972. Coronary vascular responses to stimulation of chemoreceptors and baroreceptors. Circ. Res. 31: 8-17.

22. Mudge, G. H., W. Grossman, R. M. Mills, Jr., M. Lesch, and E. Braunwald. 1976. Reflex increase in coronary vascular resistance in patients with ischemic heart disease. N. Engl. J. Med. 295: 1333-1337.

23. Blair, D. A., W. E. Glover, A. D. M. Greenfield, and I. C. Roddie. 1959. Excitation of cholinergic vasodilator nerves to human skeletal muscles during emotional stress. $J$. Physiol. (Lond.). 148: 633-647.

24. Ganz, W., K. Tamura, H. S. Marcus, R. Donoso, S. Yoshida, and H. J. C. Swan. 1971. Measurement of coronary sinus blood flow by continuous thermodilution in man. Circulation. 44: 181-195.

25. Orlick, A. E., D. R. Ricci, and D. C. Harrison. 1977. Measurement of coronary sinus blood flows: position effect. Ann. Intern. Med. 86: 112-113 (Letter to the Editor).

26. Gordy, E., and D. L. Drabkin. 1957. Spectrophotometric studies. XVI. Determination of the oxygen saturation of blood by a simplified technique applicable to standard equipment. J. Biol. Chem. 227: 285-299.

27. Yang, S. S., L. G. Bontiroglio, V. Maranhao, and H. Goldberg. 1972. In From Cardiac Catheterization Data to Hemodynamic Parameters. F. A. Davis Company, Philadelphia. 9.

28. Robinson, B. F. 1967. Relation of heart rate and systolic blood pressure to the onset of pain in angina pectoris. Circulation. 35: 1073-1083.

29. Kitamura, K., C. R. Jorgensen, F. L. Gobel, H. L. Taylor, and Y. Wong. 1972. Hemodynamic correlates of myocardial oxygen consumption during upright exercise. $J$. Appl. Physiol. 32: 516-522.

30. Stinson, E. B., J. S. Schroeder, R. B. Griepp, N. E. Shumway, and E. Dong, Jr. 1972. Observations on the behavior of recipient atria after cardiac transplantation in man. Am. J. Cardiol. 30: 615-622.

31. Stinson, E. B., R. B. Griepp, J. S. Schroeder, E. Dong, Jr., 
and N. E. Shumway. 1972. Hemodynamic observations one and two years after cardiac transplantation in man. Circulation. 45: 1183-1194.

32. Cross, C. E. 1964. Influence of coronary arterial pressure on coronary vasomotor tones. Circ. Res. 14-15(Suppl. I): I-87.

33. Mosher, P., J. Ross, Jr., P. A. McFate, and R. F. Shaw. 1964. Control of coronary blood flow by an autoregulatory mechanism. Circ. Res. 14: 250-259.

34. Rackley, C. E., H. T. Dodge, Y. D. Coble, and R. E. Hay. 1964. A method for determining left ventricular mass in man. Circulation. 29: 666-671.

35. Myers, W. W., and C. R. Honig. 1964. Number and distribution of capillaries as determinants of myocardial oxygen tension. Am. J. Physiol. 207: 653-660.
36. Gould, L., Z. Mohammad, and S. Ettinger. 1969. Phentolamine and cardiovascular performance. Br. Heart J. 31: $154-162$.

37. Miura, Y., T. Haneda, T. Sato, K. Miyazawa, H. Sakuma, K. Kobayashi, K. Minai, K. Shirato, T. Honna, T. Takishima, and K. Yoshinaga. 1976. Plasma catecholamine levels in the coronary sinus, aorta and femoral vein of subjects undergoing cardiac catheterization at rest and during exercise. Jpn. Circ. J. 40: 929-934.

38. Ganz, W., and H. J. C. Swan. 1972. Measurement of blood flow by thermodilution. Am. J. Cardiol. 29: 241-246.

39. Koberstein, R. C., D. E. Pittman, and F. J. Klocke. 1969. Right atrial admixture in coronary venous blood. Am. J. Physiol. 216: 531-535. 